\title{
Developing Indicators of Sustainable Agriculture at Farm Level
}

\author{
Waney, N.F.L. ${ }^{1,2}$, Soemarno ${ }^{3}$, Yuliaty, Y. ${ }^{4}$, Polii, B. ${ }^{5}$ \\ ${ }^{I}$ (Agricultural Sciences Graduate Program, University of Brawijaya, Indonesia) \\ ${ }_{2}^{2}$ (Department of Socio Economic, Faculty of Agriculture, University of Sam Ratulangi, Indonesia) \\ ${ }^{3}$ (Department of Soil Sciences, Faculty of Agriculture, University of Brawijaya, Indonesia) \\ ${ }^{4}$ (Department of Socio Economic, Faculty of Agriculture, University of Brawijaya, Indonesia) \\ ${ }^{5}$ (Department of Agronomy, Faculty of Agriculture, University of Sam Ratulangi, Indonesia)
}

\begin{abstract}
Farmers in Rurukan, (North Sulawesi, Indonesia), have long experience with conventional agricultural practices to vegetables farming in unsuitable upland areas. So far its negative impacts have sufficient evidence and that the actual production mode may not be sustainable. A practically-holistic measures which describe the sustainability of farming system in that area and to facilitate its assessment, had been developed through the following stages: farm characterizing, identification of critical issues, propose specific indicators for sustainability and, farmers assessment. The assessment of proposed indicators was involved local farmers, and that the indicators proposed were sorted under the most relevant key issues of sustainable farming and were arranged within the hierarchical framework of Principles, Criteria, Indicators. We proposed 20 sustainability indicators which most relate to outcome measures and partly in sustainability efforts. We also identified 8 environmental topics, 7 economic topics and 5 social topics. Farmers prefer two indicators attributed to economic aspect (farm income and output price stability) as the most important for sustainability of their farm, followed by one indicator attributed to social aspect (stakeholders supporting) and then two indicators attributed to environment aspect (erosion control and pest and disease control).
\end{abstract}

Keywords: agriculture, farming system, sustainability indicators

\section{INTRODUCTION}

Many effort has been made to increase levels of agricultural production through the use of technological innovations. One of the most well-known technological innovations which has a significant impact on increasing agricultural production was green revolution technology which rely on the use of high yielding seeds, chemical fertilizers and pesticides [1]. Conventional (modern) agriculture which characterized by highly mechanized systems with monocultures of crops, extensive use of artificial fertilizers and pesticides, capital intensive, and large scale [2], made use of the green revolution technology in an attempt to increase agricultural productivity. However, negative impacts of these developments were rarely considered. According to Kannan et al. (2005) [1] application of green revolution technology on one hand was able to answer the need for adequate food to the people on earth, but on the other hand had a significant negative impact on the environment [1]. Sustainable agriculture arises as alternatives approach to conventional agriculture [3], which including the use of on-farm or locally available resources, reduced use of synthetic fertilizers and pesticides, increased use of crop rotations and organic materials as soil ameliorates, diversification of crop and animal species and reduced stocking rates [4]. Today concerns about agricultural sustainability centre on the need to develop agricultural technologies and practices that: (i) do not have adverse effects on the environment, (ii) are accessible to and effective for farmers, and (iii) lead to both improvements in food productivity and have positive side effects on environmental goods and services [5].

As for any study on sustainable agriculture, the question arises of how agricultural sustainability can be measured. Being a concept sustainability cannot be measured directly. Appropriate indicators must be selected to determine level and duration of sustainability [6] [7]. International organizations such as WB, UN, OECD has been introduced the analysis of agricultural sustainability by the aggregation of a set of indicators into a single index. Over the last decade a great number of the different set of indicators have been developed and designed even at international level [8] [9] [10] [11] and at national level [12] [13] [14]. Furthermore, for the construction of farm level indicator of agricultural sustainability, an increasing branch of the literature has been occupied [15] [16] [17] [18]. Meanwhile, more practical environmental impact assessment (EIA) tools have been developed at the farm level, e.g. EMA [19], ECOFARM [20], AEI [21], MESMIS [22]. A review on the alternative approaches on constructing a composite indicator to agricultural sustainability can also be traced back in [23] and [24]. However, none of these indicator sets can be used at various hierarchical levels of agricultural production systems and because of the largeness of the agriculture sustainability concept, the strong assumptions in terms of amalgamation of the different attribute of the sustainability function, and the lack of objectivity in methodology, all these methods have been criticized [25]. Finally, few of these works relate to locally specific agriculture, which up til now lacked a tool for assessing the sustainability of its farms. Indicators 
used for agricultural sustainability should be location specific. They should be constructed within the context of the contemporary socioeconomic and ecological situation [26]. Even if the precise measurement of sustainability is impossible as it is site-specific and a dynamic concept [27], when specific parameters or criteria are selected, it is possible to say whether certain trends are steady, going up or going down [28].

One of the potential areas to produce highland vegetables (carrot, cabbage, onion leaves, and others) in eastern Indonesia, was in Rurukan, North Sulawesi Province. However farmers in this area have a relatively long experience with intensive agricultural practices, and so far its negative impacts have sufficient evidence exists [29] [30], that the actual production mode may not be sustainable or in other words that farming systems may loose their production function in the long term. Therefore, as a crucial property of agricultural systems, its evaluation has become a main challenge especially for us. For this reason, the indicators that represent a holistic condition of farming system and which consider its practical used was needed. This study aims at developing sustainability indicators at farm level in that area. This was achieved by:

1. Considering a holistic manner of agricultural sustainability concept- we accounts for the four levels of ontological thinking of sustainable farming system and all three pillars of sustainability as the boundaries of farming system.

2. Developing a consistent approach for constructing sustainability indicators through hierarchical framework of principles, criteria and indicators. The indicators were generated through participatory approach of identifying critical issues in the boundaries of sustainable farming system in study area, and its importancy was assessed by involving local farmer. We proposed that the participatory approach and procedure for constructing sustainability indicators was a practically scientific process that builts on combining knowledge of experts and experience of the main local stakeholders.

3. Ensuring that the tool and the indicators were built and generated on a generic methodology and remains as easy as possible to interpret and thus to use, though the set of generated indicators presented in this report is specific to Rurukan, North Sulawesi, Indonesia context.

\subsection{Description Of The Site Study}

\section{Methods}

This study was conducted in Rurukan, the centre of highland vegetables production in the province of North Sulawesi, Indonesia. The location plateau in the hills, with a gentle slope to very steep, so that if cultivate the land for vegetables farming, it will have negative impact on the environment. Even so farmers in this area still cultivate their land for various kind of vegetables. However, the location was relatively closed to the centre of consumers in Manado, the capital city of North Sulawesi Province and to the city of Bitung as a transit point for inter-island transport of vegetables to eastern Indonesia (Papua, Maluku and North Maluku).

\subsection{The Framework For Indicator Development}

In the framework of this study, one central aspect for establishing sustainability indicators was the adoption of a definite concept of sustainability. For that purpose we followed agricultural sustainable definition proposed by Lichtfouse et al. (2009, p.4): [31] "Agricultural systems are considered to be sustainable if they sustain themselves (three dimensions) over a long period of time, that is, if they are economically viable, environmentally safe and socially fair". After define the concept of sustainability, we set the boundaries of the sustainable agricultural system from the perspective of ontological thinking of sustainable farming, as proposed by Muhittin (2009) [32] in GSCM research, which encompasses four levels, ie. level-0: farm; level-1: immediate business environment; level-2: society; level-3: natural environment. Since sustainable farming should achieve three goals including environmentally sustainable, socially sustainable and economically sustainable [33], in its boundaries, so it should be put in the contex of the ontological thingking regarding sustainable farming. The time component of sustainable agriculture is about maintaining the ability of agriculture to perform significant social, environmental and social functions for present and future generations, which the scope of a sustainability assessment applies to the coming two or three generations. Next, the structure of the hierarchical framework of principles, criteria and indicators [34] was introduced. This framework was used in order to facilitate the formulation of sustainability indicators at the boundaries of sustainable farming system (Fig. 1). Principles stated about general conditions for achieving sustainabiltiy. In this study, we made use of the key principles for sustainability as proposed by Pretty, J. (2008) [5]: (i) integrate biological and ecological processes; (ii) minimize the use of those non-renewable inputs that cause harm to the environment or to the health of farmers and consumers; (iii) make productive use of the knowledge and skills of farmers; and (iv) make productive use of people's collective capacities to work together to solve common agricultural and natural resource problems. We had added some principles related to social and economic aspects likely to create effective marketing channel for sustainability of product supply and to bring wealth and happiness to family farm, local community and the whole society by offering products to meet their needs. 
Criteria for the selection and evaluation of sustainability indicators, be based on the criteria developed by Becker (1997) [35].

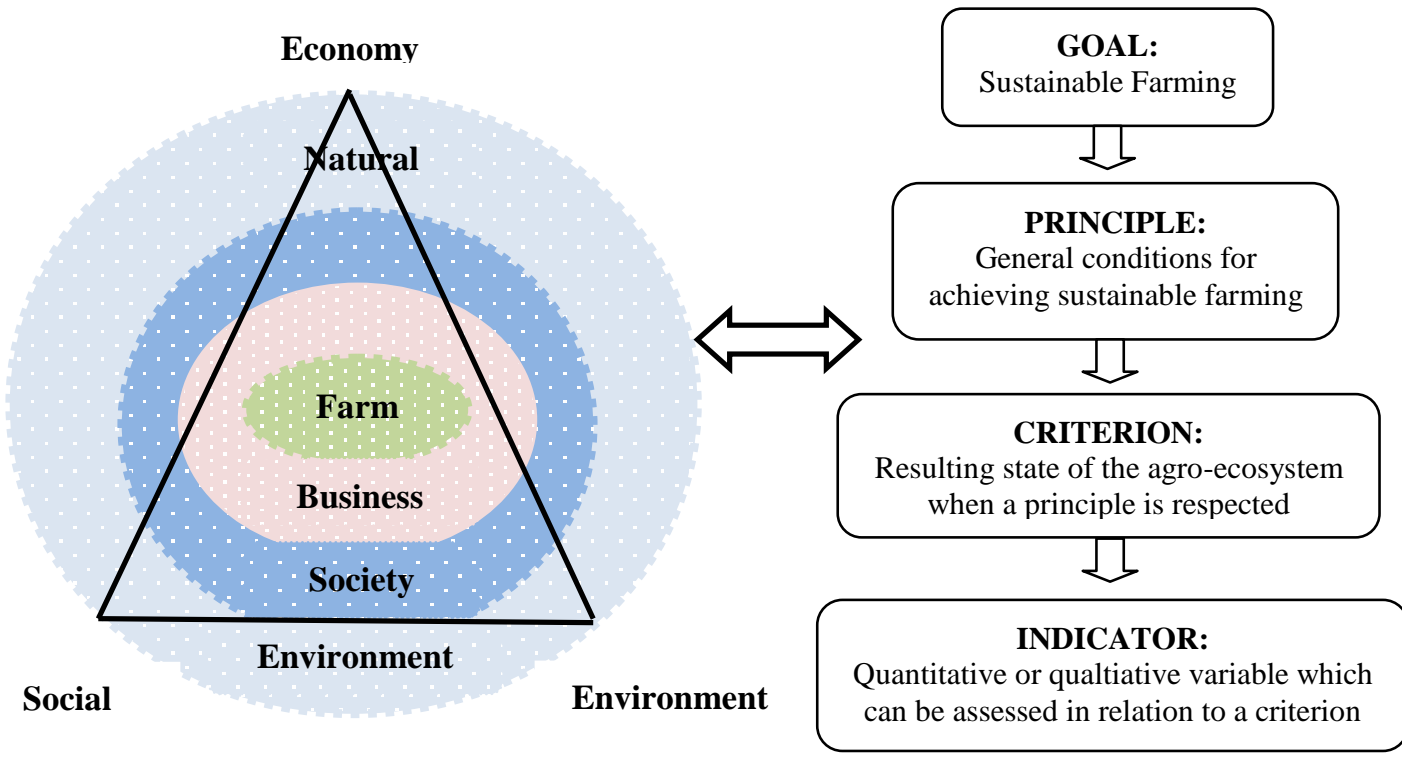

Figure. 1 Boundaries of sustainable farming system and structure of hierarchical framework of principles, criteria and indicators (Adapted from Muhittin, 2009 and Peeters A. et al., 2005)

\subsection{Procedure In Developing Sustainability Indicators}

In construction sustainability indicators, the following steps (Fig.2) were involved. Firstly, characterising farming in the site study. Afterthat, critical issues in the boundaries of sustainable farming were indentified. Then in line with sustainable farming boundaries and its three pillars, we made used of the hierarchical principles, criteria and indicators (Fig.1) to construct specific indicators of sustainability. The importancy of the indicators generating from previews step then be assessed according to farmers perspectives and preferences. We had involved 125 respondence through simple random sampling method and one group of farmers in research area to participate in the process of identification of critical issues and of assessing the indicators. At each step, the judgement was done by careful consideration because it can potentially have a substantial impact on the ultimate outcome of the indicators.

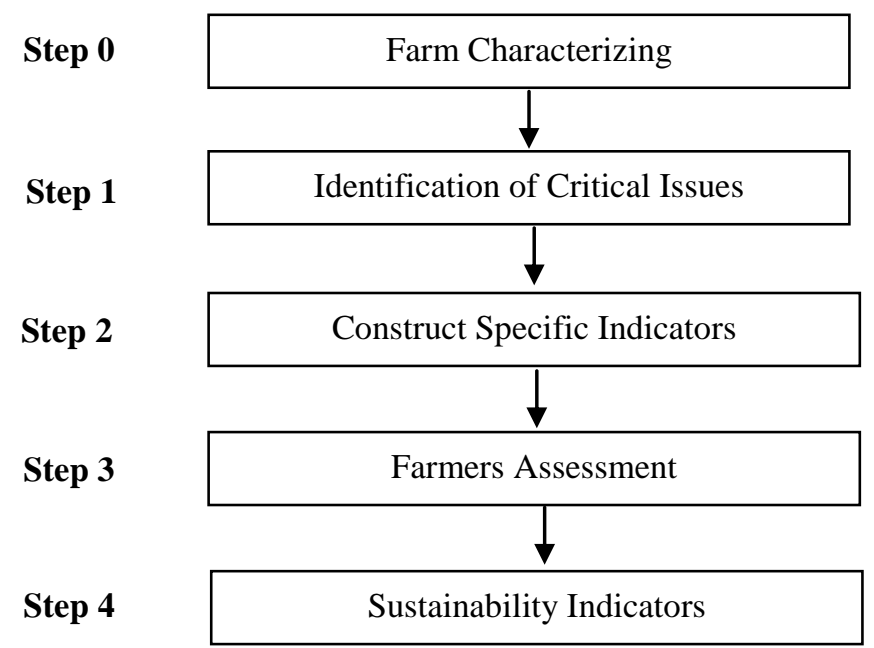

Figure. 2 Sequence of steps in developing sustainability indicator procedure

\subsection{Farm Characteristics}

III. Result

Approximately 70 percent of vegetable farmers in the study area were still using conventional methods by applying green revolution technologies, namely chemical fertilizers, insecticides, herbicides and the like and 
rely on improved seed, except for carrot. Nevertheless, about 30 percent of farmer had implemented some practices and technologies as alternative to conventional methods. Those practices and technologies include using compost, animal manure and organic fertilizers homemade, pests and diseases control in a naturally manner by using bio-insecticides (soursop leaf extract), planting decoy crops for pests and making pest trapping for leeches that attack young cabbage crops from natural materials such as banana stems. Of the eleven farm activities we identified, and the extent rate to which sustainability principles were applied and were identified, two were categorised as high, six were categorised as moderate, and three were categorised as low. Furthermore, the extent of sustainable farming principles applied in most activities on highland vegetable farming in study area were summarized in Table 1.

Table 1. Intensity of applying sustainability principles in farm activities

\begin{tabular}{|l|l|c|c|c|}
\hline \multirow{2}{*}{ No } & Farm Activities & \multicolumn{2}{|c|}{ Intensity to apply sustainability principles } \\
\cline { 3 - 4 } & & High & Moderate & Low \\
\hline 1 & Land tilth & & $\mathrm{V}$ & \\
\hline 2 & Control of pests and diseases & & $\mathrm{V}$ & \\
\hline 3 & Weed control & & $\mathrm{V}$ & \\
\hline 4 & Environmental pollution control & & & $\mathrm{V}$ \\
\hline 5 & Biodiversity & & $\mathrm{V}$ & \\
\hline 6 & Reduction in the use of external inputs & & & $\mathrm{V}$ \\
\hline 7 & Products safety & & & \\
\hline 8 & Workers earnings & $\mathrm{V}$ & $\mathrm{V}$ & \\
\hline 9 & Welfare of farm households & & & \\
\hline 10 & The involvement of local communities & $\mathrm{V}$ & $\mathrm{V}$ & \\
\hline 11 & Lingkage with related business & & & \\
\hline & Total & & & 3 \\
\hline
\end{tabular}

\subsection{Critical Issues On Vegetables Farming System}

Several important issues related to the development of highland vegetable farming in a sustainable manner based on in-depth interviews, observations and field visit are presented below :

- Approximately 80 percent of land slope are steep to very steep so there should be efforts to control erosion. Soil conservation is a key priority to ensure that today's agricultural practices do not cause erosion or affect longterm fertility. We expect farmers to work towards applying best-practice soil management adapted to their specific crops and land requirements.

- The use of synthetic chemicals substance in vegetable farming was very intens so injurious vegetable farmers, consumers health and pollute the environment. It is expected that current farm practices would minimise the impact on ecosystems and biodiversity of the land. Farmers are expected to adopt good practices such as reduced pesticide use and synthetic fertilizers, as well as the protection of native species.

- Some farm activities such as land preparation and harvesting require large amounts of labor so its availability at the time needed was crucial to farmers.

- Issues in vegetables product marketing specially at farm gate: the market is dominated by several local traders, fluctuations in the price of vegetables cause uncertainty for farm businesses, and also related issues on marketing channels of organic farming, and vegetable supply chain development.

- Issues on stakeholders supporting. In all attempts to develop sustainable farming system, the most important part was the involvement and supporting of all parties, include internal and external stakeholder.

- Issues on the adoption of alternative methods and its availability, ease of getting resources, agricultural services and government support.

- Knowledge and awareness of farmers about agricultural resources and natural resource conservation in general

- Positive role of vegetables farming in supporting local economies and livelihoods.

- Issues on product quality and safety. Production of vegetables requires ingredients that meet the highest quality and safety criteria. It is expected that farmers apply the highest possible standards of quality across seeding, growing, harvesting and storing practices.

- Ensuring fair working, a fair wage, and respect for human rights for all farm labors (e.g. small-holder farmers, temporary or seasonal labour).

\subsection{Indicators For Sustainable Farming Systems}

20 indicators of sustainable farming were generated at the end of the construction process, 12 were actually outcome-based indicators and the rest, 8 indicators were practice-based indicators. Related to the attributes (aspects) of the 20 sustainability indicators, eight indicators were related to environment or ecology, seven indicators were related to economy and five indicators were related to social. The most frequent sustainability stewardship topics, as indicated in the number of its indicators, were related to environment or ecology efforts, 
followed by economic efforts and performance, and then social efforts. The result of detailed indicators, aspects, criteria and priciples was presented in Table 2.

Table 2. The indicators of sustainable highland vegetable farming

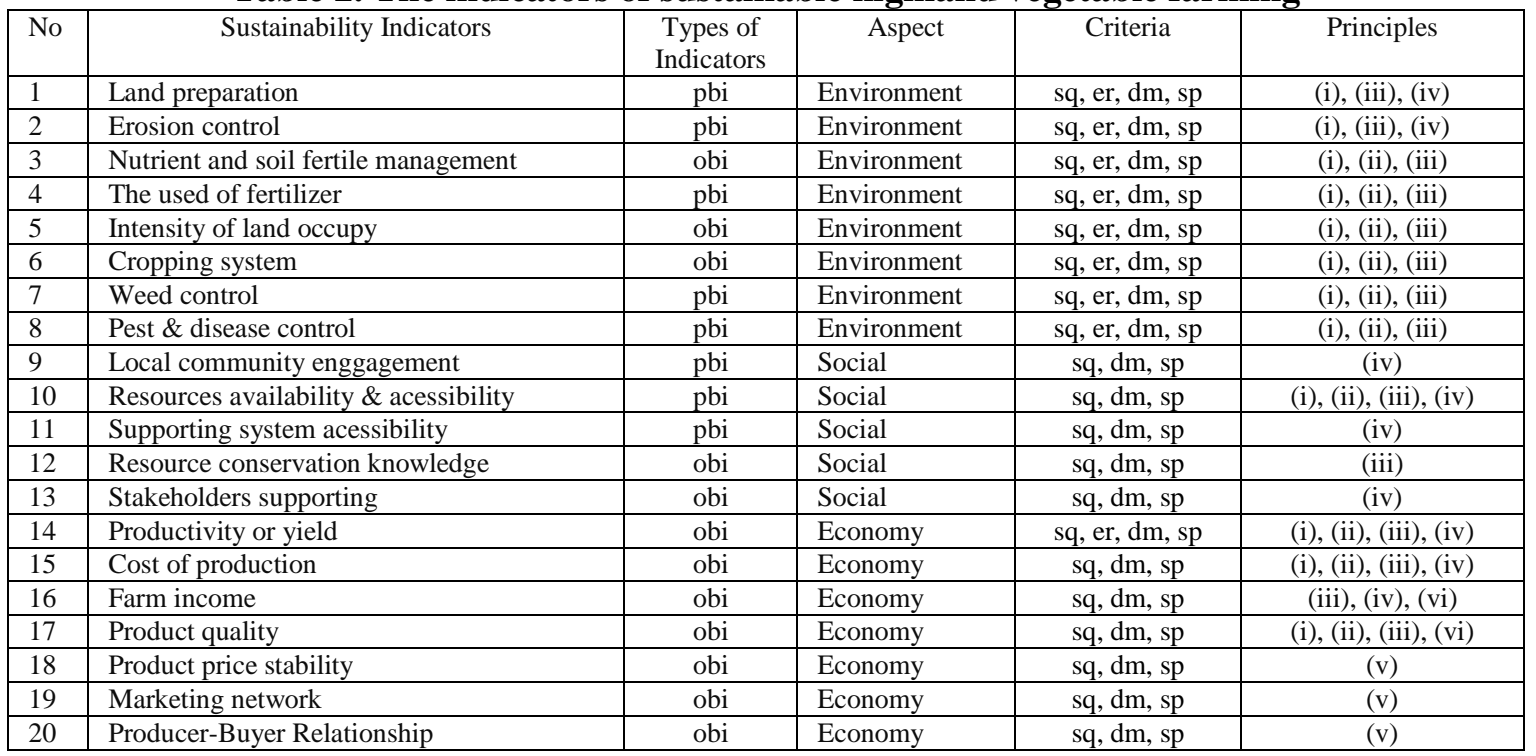

Types of indicators: $\mathrm{pbi}=$ practice-based indicator; $\mathrm{obi}=$ outcome-based indicator

Criteria: $\mathrm{SQ}=$ scientific quality, $\mathrm{ER}=$ ecosystem relevance, $\mathrm{DM}=$ data management, $\mathrm{SP}=$ sustainability paradigm.

Principles: (i) integrate biological and ecological processes, (ii) minimize the use of those non-renewable inputs, (iii) make productive use of the knowledge and skills of farmers, (iv) make productive use of people's collective capacities, (v) create effetive channel or market for sustainability of product supply, (vi) bring wealth and happiness to family farm, local community and the whole society by offering products to meet their needs.

Of the eight sellected indicators which related to environment, the most frequent sustainability stewardship topics were related to agricultural land management: land preparation, erosion control, nutrient and soil fertile management, the used of fertilizer and intensity of land occupy. The other three indicators pertain more generally to biological aspect; cropping system, weed control, and pest and disease control. Three of the seven indicators on economy were created specifically to address marketing aspects: product price stability, marketing network and producer-buyer relationship. Afterthat, two of it specifically address economic performance: farm productivity and farm income. Moreover, one had stewardship topics related to efficiency: cost of production, and another one was related to quality aspect: product quality. The most frequent social stewardship topics were related to institutional: resources availability, supporting system acessibility, knowledge about resource conservation, stakeholders supporting. Only one topic which relate to community: local community enggagement.

\subsection{The Assessment of Indicators Importancy}

The importancy of an indicator was measured on five scales, using Likert scale, that was $1,00-1,50=$ very unimportant; $1,51-2,50=$ unimportant; $2,51-3,50=$ moderate; $3,51-4,50=$ important and $4,51-5,00=$ very important, and the measurement be based on individual preference of each farmers using questionnaires. The assessment of the indicators involved 125 respondence which were chossen using simple random sampling method. Having obtained the value and the average value for each indicator, all indicators were arranged in order of rank, respectively. Given the role of farmer groups in the farming activities in the region was dominant then the same indicators were also discussed and ranked its level of importance by farmer groups through focus group discussions. The results of the group ranking which organized by the importancy of an indicator from the viewpoint of the group, were compared with the sequence order of the individual assessment and presented in Table 3. 
Table 3. Rank of the indicators of farm sustainability

\begin{tabular}{|c|c|l|l|c|}
\hline $\begin{array}{c}\text { Average } \\
\text { Value }\end{array}$ & $\begin{array}{c}\text { Individual } \\
\text { Ranking }\end{array}$ & \multicolumn{1}{|c|}{ Indicators } & Dimension & $\begin{array}{c}\text { Group } \\
\text { Rangking }\end{array}$ \\
\hline 3,40 & 15 & Land preparation & Environment & 18 \\
\hline 4,28 & 4 & Erosion control & Environment & 5 \\
\hline 4,00 & 11 & Nutrient and soil fertile management & Environment & 15 \\
\hline 4,00 & 11 & The used of fertilizer & Environment & 16 \\
\hline 3,52 & 14 & Intensity of land occupy & Environment & 19 \\
\hline 3,83 & 12 & Cropping system & Environment & 17 \\
\hline 4,00 & 11 & Weed control & Environment & 20 \\
\hline 4,28 & 4 & Pest \& disease control & Environment & 6 \\
\hline 4,11 & 7 & Local community enggagement & Social & 10 \\
\hline 4,03 & 10 & Resources availability \& acessibility & Social & 13 \\
\hline 3,05 & 16 & Supporting system acessibility & Social & 14 \\
\hline 4,05 & 9 & Resource conservation knowledge & Social & 9 \\
\hline 4,39 & 3 & Stakeholders supporting & Social & 4 \\
\hline 4,12 & 6 & Productivity or yield & Economy & 11 \\
\hline 4,09 & 8 & Cost of production & Economy & 12 \\
\hline 4,53 & 1 & Farm income & Economy & 1 \\
\hline 3,68 & 13 & Product quality & Economy & 7 \\
\hline 4,41 & 2 & Product price stability & Economy & 2 \\
\hline 4,17 & 5 & Marketing network & Economy & 3 \\
\hline 4,03 & 10 & Producer-Buyer Relationship & Economy & 8 \\
\hline
\end{tabular}

Seventeen of the twenty sustainability indicators were categorised as important (the average value between $3,51-4,50)$, those include erosion control, nutrient \& soil fertile management, the used of fertilizer, intensity of land occupy, cropping system, weed control, pests \& diseases control, local community enggagement, resources acessibility, knowledge about resources conservation, stakeholders supporting, farm productivity, cost of production, product quality, product price stability, marketing network and producer-buyer relationship. Two indicators were categorised as moderate (the average value between 2,51 - 3,50): land preparation and availability of supporting system. The only one indicator that was categorised as very important: farm income (the average value between 4,51-5,00).

Preferences of farmers to a certain indicator will determine of the extent to which the choices of farmers will be taken in order to implement the principles of sustainable farming. That preference to a certain indicator was assessed and ranked according to the perspective of farmers individually and as a group. After all indicators arranged in order of rank, respectively, there were three indicators which got similar order of rank in perspective of farmers either individually or as group: farm income, product price stability, and knowledge about resource conservation. Others indicators which had differences level in order of rank were: stakeholders supporting and erosion control, had one level differences in order of rank, then, pests and diseases control, network marketing, the producer-buyer relationship and a supporting system availability had two levels differences in order of rank, afterthat local community enggagement, acessibility resources and land preparation had three levels differences in order of rank, furthermore, cost of production, nutrient management and soil fertile had four levels differences in order of rank, moreover, farm productivity, the used of fertilizer, cropping system, and intensity of land occupy had five levels differences in order of rank. The rest, indicators such product quality had differences six levels in order of rank, and weed control had differences nine levels in order of rank.

Eventhough the environment aspect had the broadest spectrum as reflecting in the number of its indicators, instead the assessment of its significantly important actually starting from economic aspect, followed by social aspect and then ecological or environmental aspect in the last. This was actually almost the same by individual assessment and group rank. Even so, not all of the indicators on economic aspect were in the top order of rank. Adversely, not all of the indicator on social and environmental aspects rank at the bottom. In economic aspect, indicator such as farm income, product price stability and marketing network were placed on the top three positions. Furthermore indicator attributted in social such stakeholders supporting was on the fourth position from the overall ranks. It was stressing that the implementation of sustainable farming systems require the support of all parties and not just borne by the farmer. The difference in the order of importance for other indicators such as on product quality, involvement of local community, farm productivity, cost of production, easy of getting resources, cropping system, intensity of land occupy, land preparation, indicate the existence of different experiences, different views and different interests among farmers, individual and group. In addition to the dominance of certain individuals within the group influences the placement order of importance of the indicators in the group. 


\subsection{Environment Or Ecological Indicators}

Ecological or environmental aspect plays an important role in plant-based farming systems. Natural environment was a fundamental element of farming, because it provides everything that was needed in the production process of the plant. Land was the main resource of the nature and serves as a medium for plant growth. Therefore, of the 8 indicators of sustainability on ecological or environmental dimension, as many as 5 indicators directly related to the soil. Then two indicators related to plants or crops and 1 indicator related to animals. The ranking of the eight indicators of ecology or environment aspect was presented in Table 4.

Table 4. Value and rating of sustainability indicators in environmental aspect

\begin{tabular}{|l|c|c|c|}
\hline \multicolumn{1}{|c|}{ Indicators } & Value & Individual Rank & Group Rank \\
\hline Land Preparation & 3,40 & 5 & 6 \\
\hline Erosion control & 4,28 & 1 & 1 \\
\hline Nutrient \& soil fertile management & 4,00 & 2 & 3 \\
\hline The used of fertilizers & 4,00 & 2 & 4 \\
\hline Intensity of land occupy & 3,52 & 4 & 7 \\
\hline Cropping system & 3,83 & 3 & 5 \\
\hline Weed control & 4,00 & 2 & 8 \\
\hline Pests \& diseases control & 4,28 & 1 & 2 \\
\hline
\end{tabular}

Note: composition of indicator ranked by individual farmers and farmer groups had adjusted according to the order of 8 indicator on environment or ecological aspect.

Basically there were no striking differences between individual and group assessment about the rank in order of importance of the indicators on the environment component except for the weed control. Two of the eight indicators on the environment component were on the first rank in order of importance from the point of view of farmers, namely erosion control and pest and disease control. The first rank was closely related to the topograpic condition in the study area, where about 80 percent of the land has a slope steep to very steep. Therefore, it was highly likely that in the rainy season or when high intensity rainfall, erosion will occured. These conditions make erosion control became the priority for vegetable farming sustainability. In general, erosion control was done by making terraces according to the land contour. Next, pests and diseases control was also related to the type of crops grown by farmers (cabbage, carrots, mustard and the like) which very susceptible to pests and diseases attact. The intensity of pests and diseases attact, in certain season, was very high, so spraying was done continuously, starting one week after planting until harvest. Moreover, three indicators which ranks second, ie nutrient and soil fertile management, fertilizer use and weed control, were interrelated in sustaining plant growth.

Cropping system, was actually ranked parallel by the two assessors (individual and group), applying in specific manner and not as its meaning from the literature. Some farmers grow only one crop on their land. Farmers tend not to mix crops but may divide plots within the farmland for different mixtures. Part of farmers planted several types of vegetables such as cabbage, onion leaves, flower cabbage, broccoli, etc., in some areas of agricultural land that has been divided by a relatively small area. Crop rotation was generally done to keep track of the price of vegetables, so the time was uncertain. Crop rotation can be done every turn of the growing season or after a few times of planting. The main crop for monoculture was carrot and cabbage. In the separated pieces of land, several types of vegetable were planted include carrot, cabbage, chinese cabbage, mustard, and onion leaves, etc. In addition there was still very small of land planted with a variety of trees and other types of crops to maintain the population diversity of plant.

In general, farmers treat the land like a machine of producing crop, thus ignoring the biological processes that occur in it. Average transition period from first planting to the next planting was just about 2 weeks. The main considerations underlying land use is the economic demands to meet various urgent needs of farm families. Therefore, the intensity of land use was placed below in term of the interests of farmers.

Soil preparation is needed when farmer want to grow vegetables. The land preparation in highland vegetables farming include land clearing and tillage, stockpiling grass and make mounds or raised beds and terracing (contours and benches). Scarify the soil was very important to sustain the growth of vegetables, especially in the early stages. Soil preparation was placed at the bottom in order of rank of environment aspect, since it is very difficult for farmers to grow vegetables without soil cultivation by clearing the land from various types of weeds and making soil structure becomes loose so it would be good for the growth of vegetable, especially in the early stages. Basically there was a striking difference in perspectives between the individual and group assessment on the order of importance of the indicators on the environment component except for weed control. 


\subsection{Social Indicators}

Farming was present in the system value of a rural community. Therefore, the social aspect, including value systems and social institutions affect the existence and sustainability of a farming system. As noted earlier that there were 5 indicators obtained with regard to social aspect of highland vegetable farming sustainability. Rank order of the five indicators on social aspect were presented in Table 5.

Table 5. Value and rating of sustainability indicators in social aspect

\begin{tabular}{|l|c|c|c|}
\hline \multicolumn{1}{|c|}{ Indicators } & Value & Individual Rank & Group Rank \\
\hline Local community enggagement & 4,11 & 2 & 3 \\
\hline Resources availability \& acessibility & 4,03 & 4 & 4 \\
\hline Supporting system acessibility & 3,05 & 5 & 5 \\
\hline Konwledge about resource conservation & 4,05 & 3 & 2 \\
\hline Stakeholders supporting & 4,39 & 1 & 1 \\
\hline
\end{tabular}

Note: composition indicator ranked by individual farmers and farmer group was adjusted according to the order of 5 indicator in social aspects.

In sosial aspect, stakeholders supporting exist on the top ranks, both in the perpectives of individual farmers and farmer group. Farmers were at the forefront in implementing sustainable vegetable farming systems, but require the support of all stakeholders, including the parties directly involved and those who were not directly involved, but interested in the production and distribution of vegetables in a sustainable manner. Development of sustainable vegetable farming systems in study area have been constrained by the system of production and distribution were less supportive and still lack the support of all stakeholders.

The awareness of farmers on resource conservation was relatively more important than the involvement of local communities in the context of farm sustainability. Individual farmers had sufficient understanding of conservation but the involvement of local communities to be more important than just an understanding of conservation in the context of sustainable farming. That's why farmers individually likely to prefer the involvement of local communities in vegetable farming activities, than the knowledge of farmers on resource conservation in his order of rank.

Acessibility of getting resources or getting farm inputs became very important when the social life of the community was heavily influenced by pragmatism. For example, the use of organic fertilizers and compost have increased among vegetable growers since these inputs easy to obtain. On the other hand the use of pesticides still relatively high due to the ease of acquiring (practically) though farmers know the negative effects of pesticide use. The soursop leaf extracts as biopesticides had been used by farmers but it was constrained by their availability when needed. According to farmers it is easier to obtain pesticides than biopesticides. Finally, the ease of obtaining services or support services such the government programs both in terms of fostering and strengthening the group as well as in improving the capacity of farmers, was placed at the bottom, because in the long run, it may hamper the independence of farmers that affect the sustainability of farming.

\subsection{Economic Indicators}

Economic aspect inevitably had became fundamental in the context of sustainable farming. Therefore, some indicators on the economic aspects exist on the top order of rank of its importance from the perspective of farmers. Seven indicators related to economic aspect in the context of sustainable farming. The Assessment and the rank of the indicators from economic aspect were presented in Table 6.

Table 6. Value and rating of sustainability indicators on economic aspect

\begin{tabular}{|l|c|c|c|}
\hline \multicolumn{1}{|c|}{ Indicators } & Value & Individual Rank & Group Rank \\
\hline Productivity (yield) & 4,12 & 4 & 6 \\
\hline Cost of production & 4,09 & 5 & 7 \\
\hline Farm income & 4,53 & 1 & 1 \\
\hline Product quality & 3,68 & 7 & 4 \\
\hline Product price stability & 4,41 & 2 & 2 \\
\hline Marketing network & 4,17 & 3 & 3 \\
\hline Producers-buyers relationship & 4,03 & 6 & 5 \\
\hline
\end{tabular}

Note: composition indicator ranked by individual farmers and farmer groups adjusted according to the order of 7 indicators on economic aspect.

There were three indicators that have similar level in the rank either by individual assessment or by group ranking. These three indicators were farm income, product price stability and established marketing network. Four indicators have different levels in both by individual assessment and group ranking. That four indicators were farm productivity (yield), product (vegetables) quality, cost of production and producers-buyers relationship (relations with market participants and consumers). 
Revenue earned from vegetables farming and income as workers became the most important indicators especially in the context of sustainable farming. Therefor from all of the indicators we constructed, this indicators exist on the top order of rank of its importance from farmers perspectives. The next indicator was the stability of vegetables prices. There were three kind of uncertainty that most commonly faced by vegetables growers in study area. Firstly, the weather or climate uncertainty which will cause the second uncertainty, namely the uncertainty of the results. Then the uncertainty of the results combine with the uncertaity in demand causes price uncertainty. Therefore, price stability becomes an important indicator for the sustainability of a farm. The next indicator was a well-established marketing network. Marketing of vegetables will determine the level of sustainability of a vegetable farm. It is needed estabilished marketing and strong network to support the continuity of vegetables production. It is difficult to maintain the sustainability of a farming system, without it.

The following indicator which also have different level in ranking, is the product quality. In the group's view, this indicator was relatively more important than the other indicator, because product quality is the guarantee for continueing its supply and so the continuity of vegetable production. By individual farmers it was becoming less important because the imbalace position at farm gate market, where local traders (middlemen) relatively stronger than the farmer and so that they always ignore the quality of the vegetables. This condition had made perception of farmer to assume that the quality was not important. Afterthat, there were three indicators which relatively paralleled in their levels: productivity (yield), cost of production and producersbuyers relationships. Since farm productivity (yield) is almost depend the compilation of three factors: natural resource and environmental conditions and technology, so the productivity had become an important indicator in the context of sustainable farming. Cost of production and producers-buyers relationship relatively balance in their levels. In view of the individual farmer production costs directly related to the operation of the farm so that it becomes more important. Instead consider the views of the producers-buyers relationship were relatively more important for the sustainability of farming, especially post-farm activities.

\subsection{Methodological Considerations}

\section{Discussion}

Putting the three pillars of sustainability to ontological thinking of sustainable farming and the structure of the hierarchical framework of principles, criteria and indicators, was helpful in the development of sustainability indicators in study area. Identification of critical issues was carried out through in-depth interviews with farmers and field observations proved to be very effective. Group discussions help broaden and deepen the understanding of sustainability indicators obtained during the identification and construction process. Each assessment indicator involving farmers and compiled a list ranking indicator also proved to be effective and help broaden understanding of the perspective of the farmers on farm sustainability. Methodologically, the combination of research expertise and involvement of farmers as key stakeholders were particularly relevant in the context of the preparation of sustainability indicator at farm level. Incorporating external experts as important to involve farmers in the preparation of sustainable indicators [36].

\subsection{Practice (Process, Effort) or Outcome Measures}

There has been much debate about the different types of indicators in agriculture, in particular between the choice of practice (effort, process) versus outcome measures or practice-based indicators versus outcome-based indicators. Outcome measures assess whether farm practices has achieved certain results, or in other words it describes the current condition of a stewardship topic and will tell a farmer where their farm is today for that stewardship topic. While practice measures assess whether sustainability has been properly practised, or in other words it describes what you are doing to maintain or increase the quality of stewardship on your farm. Of the 20 indicators proposed in this study, 12 were actually outcome-based indicators and the rest, 8 indicators were practice-based indicators. Thus it is argued that measures of farming system process or farm status outcome are almost the same or indiference even the second (outcome based indicators) may be prefered. Practice or effort or process measures relate to what is done for the farm and assess degrees of conformity to various 'accepted standards' of sustainable practices. Practice measures might include land preparation, erosion control, the application of fertilizers, weeds control, pests and diseases control, local community involvement, resources and supporting system availability and its acessibility. In some circumstances such as the management of soil nutrient, process measures will be far more appropriate than outcome measures. Since process measures tend to be very specific, the desire to be comprehensive in the construction of all indicators, may lead to a lengthy set of indicators being included.

Outcome measures look at the effects of technology or farm practices on farm status. These include nutrient and soil fertile management, intensity of land occupy, cropping system, knowledge about resources conservation, stakeholders supporting, productivity (yield), cost of production, farm income, product quality, product price stability, marketing network, producer-buyer relationship. They can be grouped in terms of the efficient use of resources and farm performance. Outcome measures are less vulnerable to reporting errors or 
misrepresentation by any other people. While the outcome approach may be conceptually appealing it is empirically problematic and can be rejected on other grounds. These include considerations such as the fact that farming systems do not necessarily produce sustainability. Furthermore, if this notion was followed and no farm status change was effected one would have to assume zero farming system output. On the other hand, it is worth considering that whoever promote farm sustainability will be most concerned with effecting a change in farm status. Changes which are the result of technology or practice and those which result from other critical factors. This relates back to the extent to which farm status can be attributed solely to the farming practices.

\subsection{Differences in Indicators Assessment}

Basically the choice of farmer on a certain attribute or on a certain indicator greatly influenced by the preferences of farmer individually. Through in-depth interviews, observations and field visit, it was found that the priority of farmers in doing farming was to meet the immediate demanding needs of farmers and their families that were urgently required and so must be met. Very difficult to expect farmers to pay more attention to the other aspects, without fulfill their basic needs. This was consistent with other studies [37] [38] which in their study reported that farmers choose sustainability indicators closely related to the objectives that meet the immediate needs of farmers living his life, and does not refer to long-term goals or broader objectives, namely maintaining ecosystem functions.

\subsection{Sustainability Indicators Development}

The choice of indicators was most often constrained by data availability and may give an unbalanced picture of farming system. Indicators are often either opportunistic and incomplete (measuring aspects of performance that are captured in existing data), or are based on highly questionable sources of data. Either weakness can cause serious damage to the credibility of the indicators. In our experience, the choice of indicator was absolutely imperative, since a list of indicators will produce a different indicators composition and hence a different ranking. The indicators which were included in the list, will have an effect on the effort which will be expended on trying to achieve on the included indicators, at the potential expense of the excluded indicators. These excluded indicators may be as (or more) important than the included indicators but simply more difficult to measure.

\section{Conclusion}

The ontological level of sustainable farming system analysis chosen can be a significant influence on the diagnosis of sustainability. At the farm level perspective, farm need to perform well in order to maintain their existence succesfully. In this respect, particular erosion control, pest and disease control and cropping practices will be the most important determinants of sustainability. At the immediate business level perspective, to function properly in farm business environment, farmers must collaborate with some intermediaries and consumers. Therefor it is important to build a good producer-buyer relationship for farm sustainability. At the society level perspective, farming was present in the system value of a rural community. Therefore, the social aspect, including value systems and social institutions affect the existence and sustainability of a farming system. At natural environment level perspective, all resources needed for the operation of a farm, directly or indirectly, from natural environment. The way these resources were used have tremendous impacts on the sustainability of our natural environment. Moreover, Since ontological thinking means putting knowledge creation activities in its proper perspective, this study emphasizes the importance of ontological issues of sustainable farming system in line with three-pillars of sustainability to be identified.

This study also shows the importance of involving farmers as key stakeholders especially in identifying and determining the level of importance of sustainability indicators on the farm, because farmers who will decide whether or not to implement it. It was very necessary to further evaluate the level of sustainability of farming by using the proposed indicators. The difference of views between individual farmers and farmer group occur in some single indicator in all aspects include economic, social and ecological or environmental. Rather than fundamental differences of opinion but it occurs because of differences in the interpretation of the realities faced by farmers, individual farmers preferences and the possibility of a bias factor (the dominance of a particular individual in a group discussion). While no measure of sustainability can be perfect, the sustainable value, like sustainable practice, is a useful measure and describes the current sustainability performance. In view of the fact that biophysical and socioeconomic conditions in study area are site specific, those indicators which are developed in the study area may not applicable to other places.

\section{Acknowledgements}

This research was financed by Ministry of National Education, Directorate General of Higher Education, Republic of Indonesia through scholarship program. We express our grateful thanks to farmers in 
Rurukan who had voluntarily involved in this research and to village government in Rurukan for their support in our research.

\section{References}

[1] P. Kannan, A. Saravanan, S. Krishnakumar and S.K. Natarajan, Biological Properties of Soil as Influenced by Different Organic Manures. Research Journal of Agriculture and Biological Sciences, 1(2), 2005, 181-183.

[2] C.S. Smith, and G.T. McDonald, Assessing the sustainability of agriculture at the planning stage, Journal of Environmental Management, 52, 1998, 15-37.

[3] B.S. Hill, and R.J. MacRae, Developing sustainable agriculture education in Canada, Agriculture and Human Values 5, 1988, 9295.

[4] J.W. Hansen, Is agricultural sustainability a useful concept? Agricultural Systems 50, 1996, 117-143.

[5] Jules Pretty, Agricultural sustainability: concepts, principles and evidence, Phil. Trans. R. Soc. B, 363, 2008, 447-465. doi: $10.1098 /$ rstb.2007.2163.

[6] J. A. Zinck, and A. Farshad, Issues of sustainability and sustainable land management, Canadian Journal of Soil Science, 75, 1995, 407-412.

[7] S. Bell, and S. Morse, Sustainability indicators, Measuring the immeasurable (London: Earthscan Publications, 1999).

[8] D.W. Wascher, (eds.), Agri-environmental indicators for sustainable agriculture in Europe, Technical report series, European Centre for Nature Conservation, 2000, 240 pp.

[9] OECD, Environmental indicators for agriculture. Volume 3: Methods and Results, OECD, Paris, France, 2001.

[10] B. Delbaere, Environmental Risk Assessment for European Agriculture (ENRISK), European centre for nature conservation, the Netherlands, Topics, ARIADNE, International conference, Chania, Crete, Greece, November 13-15, 2002. http://www.ariadne2002.gr/paper/4-2-com-en.doc

[11] de Angelis A., Towards a sustainable agriculture and rural development agri-environmental indicators as elements of an information system for policy evaluation, Agriculture Directorate-General - European Commission, Topics, ARIADNE, International conference, Chania, Crete, Greece, November 13-15, 2002. http://www.ariadne2002.gr/paper/5-6-com-en.doc

,[12] A. Smyth, and J. Dumanski, FESLM: An international framework for evaluating sustainable land management, FAO, World Soil Resources Report 73, Rome, Italy, 1993, 74 pp.

[13] NRC (National Research Council), Ecological indicators for the nation, US National Research Council, (Washington, D.C: National academy press, 2000), 198 pp. http://www.nap.edu/catalog/9720.html

[14] MAFF (Ministry of Agriculture, Fisheries and Food), Towards sustainable agriculture, a pilot set of indicators, (London UK: MAFF Publication, 2000).

[15] M. Andreoli, and V. Tellarini, Farm sustainability evaluation: methodology and practice, Agriculture, Ecosystems \& Environment, $77(1-2), 2000$.

[16] C. Pirazzoli, and A. Castellini, Application of a model for evaluating the environmental sustainability of cultures in hill and mountain areas, The case of berries and fruit chestnut in Northern Italy, Agricultural Economics Review 1(1), 2000, 57-70.

[17] D. Rigby, P. Woodlhouse, T. Young, M. Burton, Constructing a farm level indicator of sustainable agricultural practice, Ecological Economics. 39(3), 2001, 463-478.

[18] K.J. Van Calker, P.B.M. Berentsen, C. Romero, G.W.J. Giesen, R.B.M. Huirne, Development and application of a multi-attribute sustainability function for Dutch dairy farming systems, Ecological Economics 57, 2006, 640-658.

[19] K.A. Lewis, and K.S. Bardon, EMA: A computer-based informal environmental management system for agriculture, Environ. Modell, 1998. Software 13: 123-137.

[20] A. Peeters, and V. Van Bol, ECOFARM: a research/development method for the implementation of a sustainable agriculture, In Methods and Tools of extension for mountain farms, Peeters A. (ed.), FAO, REU Technical series 57, 2000, 41-56.

[21] P. Girardin, C. Bockstaller, and H. Van der Werf, Assessment of potential impacts of agricultural practices on the environment: the AGRO-ECO method, Environmental Impact Assessment Review,20, 2000, 227-239.

[22] S. López-Ridaura, O. Masera, and M. Astier, Evaluating the sustainability of complex socioenvironmental systems, The MESMIS framework, Ecological Indicators 2, 2002, 135-148.

[23] J.A. Gomez-Limon, and L. Riesgo, Alternative approaches on constructing a composite indicator to measure agricultural sustainability, Paper prepared for presentation at the $107^{\text {th }}$ EAAE Seminar: Modelling of Agricultural and Rural Development Policies. Sevilla, Spain, January 29th-February 1st, 2008.

[24] OECD, (ed) C.R. Binder, and G. Feola, Normative, systemic and procedural aspects: a review of indicator-based sustainability assessments in agriculture, OECD, Paris, 2010.

[25] K.J. Van Calker, P.B.M Berentsen, C. Romero, G. W. J. Giesen, R.B.M Huirne, Development and application of a multi-attribute sustainability function for Dutch dairy farming systems, Ecological Economics 57, 2006, 640-658.

[26] Dariush Hayati, Zahra Ranjbar, and Ezatollah Karami, Measuring Agricultural Sustainability, In E. Lichtfouse (ed.), Biodiversity, Biofuels, Agroforestry and Conservation Agriculture, Sustainable Agriculture Reviews 5, 2010, 73-100. DOI 10.1007/978-90-4819513-8_2, () Springer Science+Business Media B.V.

[27] J. Ikerd, Two related but distinctly different concepts: organic farming and sustainable agriculture, Small Farm Today 10 (1), 1993 , $30-31$.

[28] J. N. Pretty, Regenerating agriculture: policies and practice for sustainability and self-reliance, (London: Earthscan, 1995).

[29] Pusat Penelitian Lingkungan Hidup dan Sumberdaya Alam (PPLH-SDA) Lemlit Unsrat, Monitoring Evaluasi Erosi Dan Penggunaan Lahan Secara Partisipatif Untuk Kegiatan Model Usahatani Hortikultura Berbasis Konservasi Di Das Mikro Rurukan, Laporan Hasil Penelitian, Tidak Dipublikasi, 2005.

[30] J. Nebath, J.L. Rantung dan M.R. Kereh, Kajian Residu Pestisida Pada Beberapa Jenis Sayuran Di Pasaran, Laporan Hasil Penelitian Strategis Nasional, Lembaga Penelitian Unsrat Manado, 2010.

[31] E. Lichtfouse, M. Navarrete, P. Debaeke, S. Veronique, C. Alberola, Sustainable Agriculture, Springer, France, 2009.

[32] O. Muhittin, Green Supply Chain Management Research: Ontological and Epistemological Issues, Paper Interuniversity Research Center on Enterprise Network, Logistic and Transportation (CIRRELT), 57, 2009.

[33] Attra, Applying The Principle of Sustainable Farming, 2003. www.attra.ncat.org.

[34 ] A. Peeters, C. Bielders, M. Hermy, E. Mathijs, B. Muys, M. Vanclooster, Framework for assessing sustainability levels in Belgian agricultural systems - safe, Part 1: Sustainable production and consumption patterns, Final Report, Scientific Support Plan For A Sustainable Development Policy (SPSD II), CP/28, 2005. 
[35] B. Becker, Sustainability assessment: a review of values, concepts, and methodological approaches, Consultative Group on International Agricultural Research, The World Bank, Washington, DC, USA, 1997, 70.

[36] D. Rigby, D. Howlett, P. Woodhouse, A review of Indicators of Agricultural and Rural Livelihood Sustainability, Sustainability Indicators for Natural Resource Management \& Policy, Working Paper No.1, Department for International Development, University of Bradford, UK, 2000. [online] URL: http://les.man.ac.uk/ses/research/CAFRE/indicators/wp1.pdf.

[37] E. Cromwell, P. Kambewa, R. Mwanza, R. Chirwa, Impact assessment using participatory approaches: "Starter Pack" and sustainable agriculture in Malawi, Agricultural Research \& Extension Network, Paper No. 112, ODI, UK, 2001. [online] URL: http://www.odi.org.uk/networks/agren/papers/agrenpaper_112.pdf.

[38] S. Vilei, Participatory evaluation of sustainability of farming systems in the Philippines, Dissertation to the Faculty of Agricultural Sciences, Institute for Farm Management, University of Hohenheim, Germany, 2010. 